\title{
Methods for detecting Gemmata spp. bacteremia in the microbiology laboratory
}

\author{
Jacques-Robert Christen ${ }^{1,2}$, Edwin Edmond ${ }^{1}$ and Michel Drancourt ${ }^{1 *}$ (])
}

\begin{abstract}
Objective: Gemmata bacteria are fastidious, Gram-negative and aerobic. The only representatives are Gemmata obscuriglobus and Gemmata massiliana. These Planctomycetes appear to be a part of human digestive tract microbiome, and G. massiliana has been isolated from water. Further specific detection in the blood of two patients with febrile neutropenia suggests that Gemmata bacteremia may remain under-documented. The objective of this study was to develop an effective protocol to document Gemmata spp. bacteremia in the laboratory. Using mock-infected and control blood specimens, three methods for detecting Gemmata bacteremia, namely, automated microbial detection, culture on solid medium, and quantitative polymerase chain reaction (PCR), have been developed and studied.

Results: Gemmata spp. were undetected by automated blood culture system but culturing mock-infected blood on Caulobacter agar detected $\geq 10^{2} \mathrm{G}$. obscuriglobus bacteria/mL and $\geq 10^{4} \mathrm{G}$. massiliana bacteria/mL. Specific real-time PCR detected $10^{2}$ Gemmata bacteria/mL. These protocols may be used to investigate the epidemiology of Gemmata spp. bacteremia.
\end{abstract}

Keywords: Gemmata, Planctomycetes, Bacteremia, Gemmata massiliana, Gemmata obscuriglobus, PCR, Culture

\section{Introduction}

Bacteria of the genus Gemmata belong to the PVC superphylum (Planctomycetes-Verrucomicrobia-Chlamydia), phylum Planctomycetes [1]. These Gram-negative fastidious bacteria are resistant to most of the routinely used antibiotics [2]. Intracellular compartmentalization and multiplication by budding are two further remarkable characteristics of Planctomycetes and Gemmata [3].

The only two cultured Gemmata representatives are Gemmata obscuriglobus [1] and Gemmata massiliana [4]. Specific DNA sequences have been detected in the digestive microbiota [5]. The PVC member Akkermansia muciniphila has been directly sequenced from stools $[6$, 7] and cultured [8]. DNA sequences detected by polymerase chain reaction (PCR) amplification-sequencing in the blood of two patients with febrile neutropenia were more closely related to Gemmata spp. sequences [9].

\footnotetext{
*Correspondence: michel.drancourt@univ-amu.fr

1 URMITE, UMR CNRS 7278, IRD 198, INSERM 1095, IHU Méditerranée Infection, Aix Marseille Université, 19-21 Bd Jean Moulin, 13005 Marseille, France

Full list of author information is available at the end of the article
}

However, detection of Gemmata bacteria in blood are currently limited to PCR-sequencing methods [9] which cannot be routinely implemented to investigate the epidemiology of Gemmata bacteremia [10]. Gemmata DNA is not detected by PCR targeting the $16 \mathrm{~S}$ ribosomal ribonucleic acid (rRNA) routinely used in microbiology laboratory [11]. This so-called "universal" bacterial gene does have sequence variations among several bacteria genera, and the "universal" primers thought to target any bacterial 16S rRNA gene do not hybridize with the specific Gemmata 16S rRNA gene sequence.

The objective of this study was to develop tools to be further implemented in the routine clinical microbiology to detect Gemmata spp. bacteremia and further assess its epidemiology.

\section{Main text}

Mock-infected blood samples preparation

G. obscuriglobus (DSM 5831 ${ }^{\mathrm{T}}$ ) and G. massiliana (DSM $26013^{\mathrm{T}}$ ) purchased from the Deutsche Sammlung von Mikrorganismen and Zellkuturen (Braunshwing, Germany) were plated on Caulobacter solid medium 
containing $2 \mathrm{~g} / \mathrm{L}$ Bacto peptone (Sigma-Aldrich, SaintQuentin Fallavier, France), with $1 \mathrm{~g} / \mathrm{L}$ yeast extract (Sigma-Aldrich) and $0.2 \mathrm{~g} / \mathrm{L} \quad \mathrm{MgSO}_{4}$ heptahydrate (Sigma-Aldrich) at $30{ }^{\circ} \mathrm{C}$ for 21 days [12]. Growing colonies were identified by matrix-assisted laser desorption ionisation-time of flight mass spectrometry (MALDITOF-MS) (Bruker Daltonics, Weissemburg, France) and a local database able to identify Planctomycetes thanks to a reproducible, unique protein profile comprising 23-39 peaks ranging in size from 2403 to $12,091 \mathrm{Da}$ and differentiating the different species $[13,14]$ and specific PCR- sequencing of the Planctomycetes 16S rRNA $[5,15]$. A $10^{6}$ bacteria/mL suspension was prepared in Hank's balanced salt solution (HBSS) (Gibco, Waltham, MA) for each Gemmata species by using KOVA Glasstic Slides 10 (Hycor Biomedical, Indianapolis, IN) for counting viable bacteria after staining with Trypan blue (vital staining) (Eurobio, Courtaboeuf, France). Whole unqualified human blood was obtained from the Etablissement Français du Sang, Marseille, France. This procedure requires no specific ethical agreement in France as these anonymized blood specimens are regarded as left-over specimens.

The level of Gemmata spp. bacteremia is unknown, and we used a detection threshold of $10^{4}$ bacteria $/ \mathrm{mL}$ of blood corresponding to reported blood inoculums for other Gram-negative bacteria such as Klebsiella pneumoniae or Aeromonas hydrophila [16]. A $10^{4}$ bacteria/ $\mathrm{mL}$ blood specimen was prepared by pouring $5 \mathrm{~mL}$ blood and $50 \mu \mathrm{L}$ the $10^{6}$ bacteria/mL HBSS suspension in an aerobic blood culture bottle (Versatrek, Waltham, USA); or by gently pouring $3 \mathrm{~mL}$ blood and $30 \mu \mathrm{L}$ of the bacterial suspension into an ethylenediaminetetraacetic acid (EDTA) tube or a heparinized tube (BD Diagnostics, Le Pont de Claix, France). Heparin and EDTA are used as anticoagulant molecules preventing clot formation, thus allowing working with whole blood. All these manipulations were performed in quadruplicate using the prepared solutions of HBSS in order to obtain mock-infected blood containing $10^{3}, 10^{2}$ and $10^{1}$ bacteria/mL of blood and negative controls incorporating the same volume of non-inoculated HBSS.

\section{Automated blood culture system}

Mock-infected and negative control bottles were incubated in the Versatrek blood culture machine at $37{ }^{\circ} \mathrm{C}$ with constant stirring for a total of four 7-day runs. After a 7-day incubation period, $0.1 \mathrm{~mL}$ of the solution sampled in half of the bottles was plated on Caulobacter agar for subculture as described below in order to look for a bacterial persistence or growth that would not have been detected by the automated system. The same was done after 14 days of incubation for the remaining bottles.

\section{Culture on solid medium}

EDTA and heparinized tubes were incubated immediately after preparation at $37{ }^{\circ} \mathrm{C}$ for $24-72 \mathrm{~h}$ to prevent misinterpretation by immediate plating after the inoculation of the tubes with bacteria and to look for bacterial growth in the tubes. Then, $0.1 \mathrm{~mL}$ of each tube was plated onto Caulobacter agar incubated at $30{ }^{\circ} \mathrm{C}$ for 21 days [1]. The number of colonies was determined weekly by visual inspection of plates.

\section{Development of a Gemmata specific qPCR system}

A real-time PCR specific to this work was designed for detecting Gemmata spp. rpoB gene. We chose rpoB gene as one of the few universal bacterial genes whose sequence has been shown to accurately identify closely related bacterial species [17]. Primers and probes were selected using primer3 software [18, 19], primerBlast [20] and The Sequence Manipulation Suite [21]. Primers and probe specificity was tested in silico by a BLAST analysis against all sequences deposited in GenBank database (May, 2016). The specificity was then experimentally assessed using the DNA extracted from G. massiliana, G. obscuriglobus and 90 other bacterial species (Additional file 1). Three negative controls (containing the PCR mix without DNA) and two positive controls (containing the mix and G. massiliana DNA or G. obscuriglobus DNA) were used for the validation of the results. Realtime PCR assays were conducted in $20 \mu \mathrm{L}$-volume containing $5 \mu \mathrm{L}$ DNA, $10 \mu \mathrm{L}$ PCR mix (Eurogentec, Angers, France), $3.5 \mu \mathrm{L}$ sterile water, $0.5 \mu \mathrm{L}$ the forward primer $5^{\prime}$-GCAAGCTCAACTCGCTCAAC-3' $(40 \mathrm{nmol} / \mathrm{L})$, $0.5 \mu \mathrm{L}$ the reverse primer $5^{\prime}$-CTTCGAGATGACGCC CTTGT-3 (40 nmol/L), (Eurogentec) and $0.5 \mu \mathrm{L}$ TaqMan MGB probe labeled with the fluorophore FAM $65^{\prime}$-ATG GTGAAGGTCTACGTCGC-3' (6 nmol/L) (Applied Biosystems, Courtaboeuf, France). The amplification cycle consisted of 2-min pre-incubation at $50{ }^{\circ} \mathrm{C}$ followed by 15-min denaturation at $95{ }^{\circ} \mathrm{C}$ and 46 cycles of $30 \mathrm{~s}$ at $95^{\circ} \mathrm{C}$ and $1 \mathrm{~min}$ at $58{ }^{\circ} \mathrm{C}$. The sample was cooled at $45^{\circ} \mathrm{C}$ for $30 \mathrm{~s}$. The qPCR was used to quantify the detection of Gemmata organisms in mock-infected blood specimens and negative controls. All DNA extractions were performed on EZ1 advanced XL using EZ1 DNA Investigator Kit (Qiagen, Courtaboeuf, France), suitable for purification of DNA from whole blood with heparin or EDTA.

\section{Statistical methods}

The statistical analyses were done using $\mathrm{R}$ Statistical Software (Foundation for Statistical Computing, Vienna, Austria). We used the Fisher's exact test. For all statistical analyses, a $\mathrm{p}<0.05$ was considered significant. 


\section{Results}

\section{Automated blood culture system}

No bacterial growth was detected by the automated blood culture system, regardless of the Gemmata species, the bacterial concentration $\left(10^{5}, 10^{4}, 10^{3}, 10^{2}\right.$, or $10^{1}$ bacteria $/ \mathrm{mL}$ of blood) and the incubation time $(7,14$ or 30 days). No growth was detected for negative controls incubated during 7,14 , or 30 days.

\section{Culture on Caulobacter medium}

No growth was detected in the negative control plates and in the plates inoculated with the blood culture bottles incubated for 7 or 14 days. Likewise, no Gemmata colony was observed in the plates inoculated with blood from EDTA or heparin tubes incubated for $72 \mathrm{~h}$ at $37^{\circ} \mathrm{C}$ before plating. G. massiliana colonies were observed on 5/32 agar plates seeded with mock-infected EDTA or heparin blood tubes inoculated with $10^{4}$ bacteria/mL incubated for $24 \mathrm{~h}$, but not for the other tested inocula. Significantly more G. obscuriglobus (18/32, detection up to an initial concentration of $10^{2}$ bacteria/mL) were detected ( $\mathrm{p}=0.004,95 \%$ confidence interval (IC 95\%) [1.53-21.52]). Growth was observed after a 14-day incubation period for G. obscuriglobus and a 21-day incubation period for G. massiliana (Table 1).
qPCR

When we tested the specificity of the qPCR here reported, G. massiliana (cycle threshold: 26.6) and G. obscuriglobus (cycle threshold: 27.1), DNA was detected, and the qPCR was negative for all the 90 other DNAtested bacterial species (Additional file 1). No Gemmata spp. DNA was detected from any of the negative controls while positive controls were detected in all experiments with $\mathrm{Ct}$ values of $27.97 \pm 0.76$.

Nine out of sixteen qPCR performed on samples extracted from blood culture bottles were positive after a 7-day incubation period for G. massiliana and 5/16 for G. obscuriglobus ( $\mathrm{p}=0.285$, IC 95\% [0.54-15.45]). After a 14-day incubation period, only 6/32 qPCR reactions were positive ( $\mathrm{p}=0.058$, IC 95\% [0.97-12.62]) (Table 2).

Twenty-nine out of 32 qPCR performed on samples extracted from EDTA and heparin tubes were positive for G. obscuriglobus whereas 23/32 were positive for $G$. massiliana ( $\mathrm{p}=0.107$, IC 95\% [0.80-23.72]). There was no detection of G. massiliana in the tubes containing $10^{1}$ bacteria/mL of blood. For the other inocula, 23/24 detections were positive in qPCR (Additional file 2: Table $\mathrm{S} 1)$. qPCR results allowed to draw calibration curves for the two Gemmata species (Fig. 1).

Table 1 Number of colonies observed after a 24-h inoculation at $37^{\circ} \mathrm{C}$ on Caulobacter medium of Gemmata sp. mockinfected blood in EDTA and heparin tubes

\begin{tabular}{|c|c|c|c|c|c|c|c|c|c|c|c|c|}
\hline \multirow[b]{2}{*}{ Initial concentration (bacteria/mL) } & \multicolumn{3}{|c|}{$\begin{array}{l}\text { Gemmata massiliana } \\
\text { EDTA tubes }\end{array}$} & \multicolumn{3}{|c|}{$\begin{array}{l}\text { Gemmata massiliana } \\
\text { Heparin tubes }\end{array}$} & \multicolumn{3}{|c|}{$\begin{array}{l}\text { Gemmata obscuriglobus } \\
\text { EDTA tubes }\end{array}$} & \multicolumn{3}{|c|}{$\begin{array}{l}\text { Gemmata obscuriglo- } \\
\text { bus } \\
\text { Heparin tubes }\end{array}$} \\
\hline & $10^{2}$ & $10^{3}$ & $10^{4}$ & $10^{2}$ & $10^{3}$ & $10^{4}$ & $10^{2}$ & $10^{3}$ & $10^{4}$ & $10^{2}$ & $10^{3}$ & $10^{4}$ \\
\hline \multirow[t]{4}{*}{ Culture results (CFU/mL) } & 0 & 0 & 200 & 0 & 0 & 320 & 0 & 90 & 300 & 70 & 270 & 420 \\
\hline & 0 & 0 & 0 & 0 & 0 & 0 & 0 & 170 & 450 & 70 & 180 & 570 \\
\hline & 0 & 0 & 480 & 0 & 0 & 0 & $\dagger$ & 0 & 400 & 20 & 410 & 550 \\
\hline & 0 & 0 & 250 & 0 & 0 & 980 & 30 & $\dagger$ & 380 & 0 & 50 & 500 \\
\hline
\end{tabular}

No colony was observed for an initial concentration of $10^{1}$ bacteria $/ \mathrm{mL}$

CFU, colony-forming unit; $\uparrow$, contaminated

Table 2 Ct values observed after qPCR amplification of Gemmata sp. DNA extracted from mock-infected blood culture bottles

\begin{tabular}{|c|c|c|c|c|c|c|c|c|c|c|c|c|c|c|c|c|}
\hline \multirow[t]{2}{*}{ Initial concentration (bacteria/mL) } & \multicolumn{4}{|c|}{$\begin{array}{l}\text { Gemmata massiliana } \\
\text { Incubation: } 7 \text { days }\end{array}$} & \multicolumn{4}{|c|}{$\begin{array}{l}\text { Gemmata obscuriglobus } \\
\text { Incubation: } 7 \text { days }\end{array}$} & \multicolumn{4}{|c|}{$\begin{array}{l}\text { Gemmata massiliana } \\
\text { Incubation: } 14 \text { days }\end{array}$} & \multicolumn{4}{|c|}{$\begin{array}{l}\text { Gemmata obscuriglo- } \\
\text { bus } \\
\text { Incubation: } 14 \text { days }\end{array}$} \\
\hline & $10^{1}$ & $10^{2}$ & $10^{3}$ & $10^{4}$ & $10^{1}$ & $10^{2}$ & $10^{3}$ & $10^{4}$ & $10^{1}$ & $10^{2}$ & $10^{3}$ & $10^{4}$ & $10^{1}$ & $10^{2}$ & $10^{3}$ & $10^{4}$ \\
\hline \multirow[t]{4}{*}{ qPCR results $(C T)$} & 38.1 & 35.7 & - & 36.1 & - & - & 35.6 & - & - & & - & 33.7 & - & - & - & - \\
\hline & - & - & - & 35.0 & - & - & 36.9 & 38.3 & - & - & - & 35.1 & - & - & - & 38.3 \\
\hline & - & 35.5 & 36.2 & 33.2 & - & - & - & - & - & - & - & 36.0 & - & - & - & 37.4 \\
\hline & - & - & 34.1 & 33.6 & - & 38.1 & 37.0 & - & - & - & - & 32.1 & - & - & - & - \\
\hline
\end{tabular}

-, no amplification detected; CT, cycle threshold 


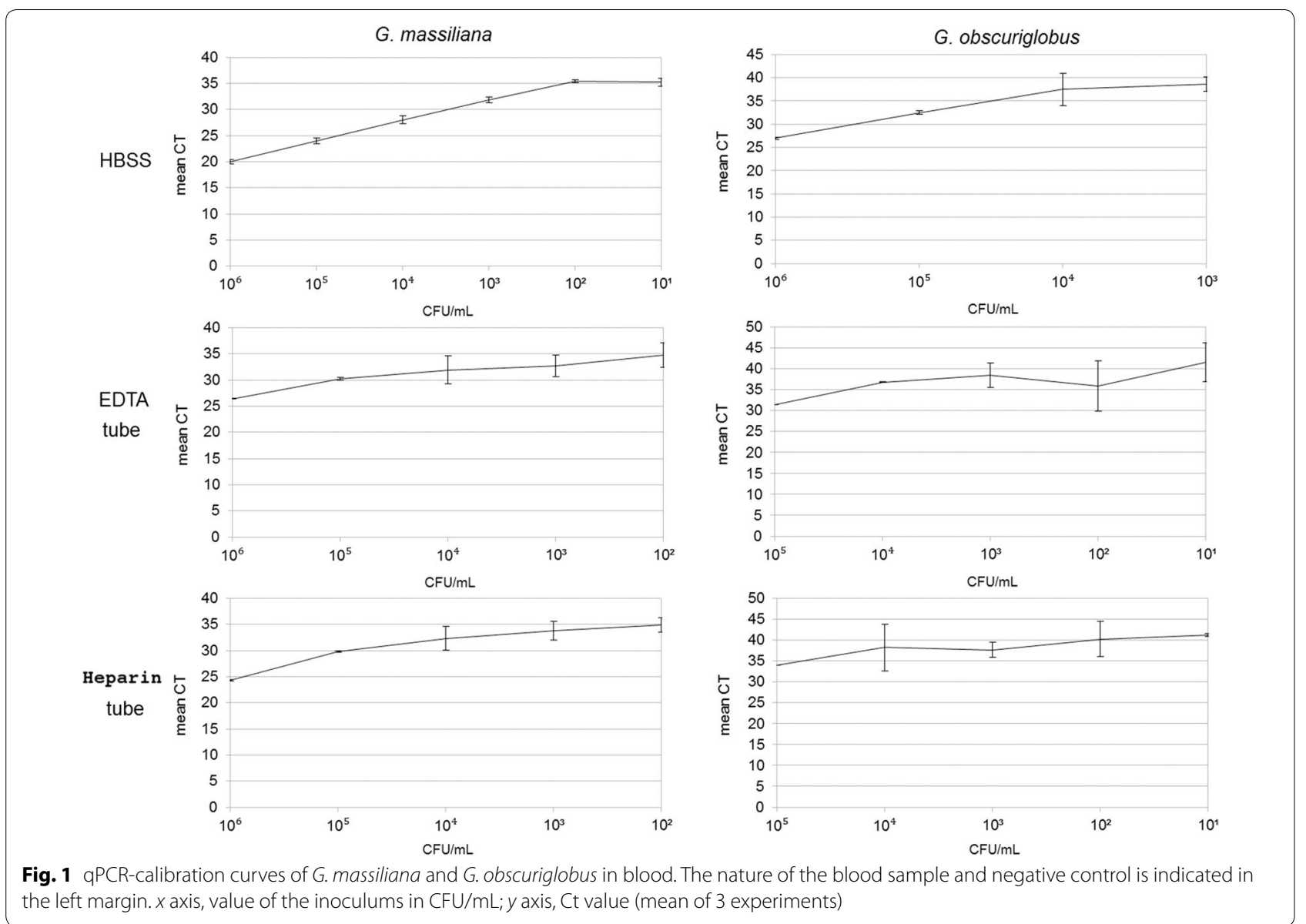

Overall, qPCR detected significantly more (52/64) Gemmata spp.-mock-infected blood in EDTA and heparin tubes than in culture on Caulobacter medium (23/64, $\mathrm{p}<0.001$, IC 95\% [3.22-18.98]).

\section{Discussion}

We previously reported the PCR-sequencing-based detection of Gemmata sequences in whole blood collected from two patients with undocumented febrile neutropenia [6]. This unique observation led us to the hypothesis according to which Gemmata bacteria could be responsible for opportunistic bacteremia after digestive translocation in neutropenic patients [5]. To further explore this hypothesis, it was necessary to develop additional laboratory tools which could be used for the routine screening of blood culture bottles, in order to further assess the epidemiology of Gemmata bacteremia in these patients.

Here, we confirm that Gemmata bacteria are not detectable in whole blood by automated microbial detection systems for blood cultures. Gemmata bacteria incubated in these blood bottles for 7 days did not grow, since no bacterial growth was observed on appropriate Caulobacter agar medium. It is possible that the incubation temperature $\left(37^{\circ} \mathrm{C}\right)$ in the automated system may not have been uniformly optimal throughout, but it does not explain the absence of growth in Gemmata spp which are able to grow at $30{ }^{\circ} \mathrm{C}$ [22]. The continuous agitation of the blood bottles may be an additional deleterious factor, but that does not explain the lack of Gemmata growth in non-agitated EDTA and heparin tubes incubated for $72 \mathrm{~h}$ at $37^{\circ} \mathrm{C}$. The most likely hypothesis is that a 7-day contact of Gemmata bacteria with whole blood collected from non-aplastic blood donors allowed for blood components to elicit bactericidal activity against Gemmata bacteria, at $37{ }^{\circ} \mathrm{C}$ under agitation. Nevertheless, our observations coupled with the lack of any reported case of culture-proven Gemmata bacteremia, even in aplasic patients, strongly suggest that blood culture automatons may not be able to accurately detect Gemmata in blood.

Therefore, we aimed at designing further culture-based detection of Gemmata bacteremia and showed that direct plating of freshly collected blood on Caulobacter agar medium could allow to detect $10^{4}$ bacteria $/ \mathrm{mL}$ of 
blood. However, the 21-day delay needed for Gemmata growth limits this method as a first-line screening of blood cultures.

We therefore developed a Gemmata-specific qPCR as a screening method. After confirming the specificity of this method for the detection of Gemmata DNA, we observed that this technique offered the highest sensitivity in our study, allowing for the detection of $10^{2}-10^{4}$ Gemmata bacteria/ml of blood drawn in either EDTA or heparinized tubes.

\section{Conclusions}

This methodological study sets up the bases for the routine detection of Gemmata bacteremia and we are now routinely screening aerobic blood culture bottles collected in aplastic patients by using the rpoB gene sequence-based qPCR here reported; followed by plating qPCR-positive blood specimens on Caulobacter agar medium as reported here. This technical report may prompt the search for blood-borne Gemmata species in other clinical microbiology laboratories serving clinical departments for aplastic patients.

\section{Limitations}

The results here exposed come from an experimental study and thus depend on the experimental conditions here reported, including the culture media and the inocula. Therefore, the generalization of observations here made with one of the few commercially available bloodculture automatons compared to the other routinely available systems (Bactec, Becton-Dickinson, and BacTALERT, bioMérieux, Marcy-l'Etoile, France) deserves to be verified by other studies. These results are a basis to investigate clinical specimens, but the experimental conditions here reported may differ from the actual conditions of clinical specimens.

\section{Additional files}

Additional file 1.93 bacterial species from which DNA was extracted to assess the specificity of $\mathrm{qPCR}$ in vitro.

Additional file 2: Table S1. qPCR performed on samples extracted from EDTA and heparin tubes.

\footnotetext{
Abbreviations

DNA: deoxyribonucleic acid; RNA: ribonucleic acid; rRNA: ribosomal ribonucleic acid; CSUR: Collection de souches de l'Unité des Rickettsies (Marseilles, France); (T: cycle threshold; DSMZ: Deutsche Sammlung von Mikrorganismen and Zellkuturen (Braunshwing, Germany); HBSS: Hank's balanced salt solution; MALDI-TOF: Matrix Assay Laser Desorption lonisation-Time Of Flight; PCR: polymerase chain reaction; qPCR: real-time PCR; spp.: species pluralis; CFU: colony-forming unit; USA: United-States of America.
}

\section{Authors' contributions}

$J R C$ and EE performed experiments and interpreted the experimental data. MD designed the experiments. JRC and MD drafted the manuscript. All authors read and approved the final manuscript.

\section{Author details}

${ }^{1}$ URMITE, UMR CNRS 7278, IRD 198, INSERM 1095, IHU Méditerranée Infection, Aix Marseille Université, 19-21 Bd Jean Moulin, 13005 Marseille, France. ${ }^{2}$ Department of Infectious Diseases and Tropical Medicine, Laveran Military Teaching Hospital, Marseille, France.

\section{Acknowledgements}

None to declare.

\section{Competing interests}

The authors declare that they have no competing interests.

\section{Availability of data and materials}

The datasets used and/or analyzed during the current study are available from the corresponding author upon reasonable request.

\section{Consent for publication \\ Not applicable.}

Ethics approval and consent to participate

Not applicable.

\section{Funding}

This work was funded by the IHU Méditerranée Infection, Marseille, France.

\section{Publisher's Note}

Springer Nature remains neutral with regard to jurisdictional claims in published maps and institutional affiliations.

Received: 24 May 2017 Accepted: 29 December 2017

Published online: 08 January 2018

\section{References}

1. Franzmann PD, Skerman VB. Gemmata obscuriglobus, a new genus and species of the budding bacteria. Antonie Van Leeuwenhoek. 1984;50(3):261-8.

2. Fuerst JA, Sagulenko E. Beyond the bacterium: Planctomycetes challenge our concepts of microbial structure and function. Nat Rev Microbiol. 2011;9(6):403-13.

3. Sagulenko E, Nouwens A, Webb Rl, Green K, Yee B, Morgan G, et al. Nuclear pore-like structures in a Compartmentalized bacterium. PLoS ONE. 2017;12(2):e0169432.

4. Aghnatios R, Drancourt M. Colonization of hospital water networks by Gemmata massiliana, a new Planctomycetes bacterium. Curr Microbiol. 2015;71(3):317-20.

5. Cayrou C, Sambe B, Armougom F, Raoult D, Drancourt M. Molecular diversity of the Planctomycetes in the human gut microbiota in France and Senegal. APMIS. 2013;121(11):1082-90.

6. Dubourg G, Lagier J-C, Armougom F, Robert C, Audoly G, Papazian L, et al. High-level colonisation of the human gut by Verrucomicrobia following broad-spectrum antibiotic treatment. Int J Antimicrob Agents. 2013;41(2):149-55.

7. Caputo A, Dubourg G, Croce O, Gupta S, Robert C, Papazian L, et al. Whole-genome assembly of Akkermansia muciniphila sequenced directly from human stool. Biol Direct. 2015;10:5.

8. Dubourg G, Cornu F, Edouard S, Battaini A, Tsimaratos M, Raoult D. First isolation of Akkermansia muciniphila in a blood culture sample. Clin Microbiol Infect. 2017;23(9):682-3. 
9. Drancourt M, Prebet T, Aghnatios R, Edouard S, Cayrou C, Henry M, et al. Planctomycetes DNA in febrile aplastic patients with leukemia, rash, diarrhea, and micronodular pneumonia. J Clin Microbiol. 2014;52(9):3453-5.

10. Aghnatios R, Drancourt M. Gemmata species: Planctomycetes of medical interest. Future Microbiol. 2016;11:659-67.

11. Drancourt $M$, Berger $P$, Raoult D. Systematic $16 S$ rRNA gene sequencing of atypical clinical isolates identified 27 new bacterial species associated with humans. J Clin Microbiol. 2004;42(5):2197-202.

12. Poindexter JS. Biological properties and classification of the Caulobacter Group. Bacteriol Rev. 1964;28:231-95.

13. Seng P, Drancourt M, Gouriet F, La Scola B, Fournier P-E, Rolain JM, et al. Ongoing revolution in bacteriology: routine identification of bacteria by matrix-assisted laser desorption ionization time-of-flight mass spectrometry. Clin Infect Dis. 2009;49(4):543-51.

14. Cayrou C, Raoult D, Drancourt M. Matrix-assisted laser desorption/ionization time-of-flight mass spectrometry for the identification of environmental organisms: the Planctomycetes paradigm. Environ Microbiol Rep. 2010;2(6):752-60.

15. Armougom F, Raoult D. Use of pyrosequencing and DNA barcodes to monitor variations in Firmicutes and Bacteroidetes communities in the gut microbiota of obese humans. BMC Genom. 2008;9:579.

16. Shenep JL, Flynn PM, Barrett FF, Stidham GL, Westenkirchner DF. Serial quantitation of endotoxemia and bacteremia during therapy for Gramnegative bacterial sepsis. J Infect Dis. 1988;157(3):565-8.
17. Mollet C, Drancourt M, Raoult D. rpoB sequence analysis as a novel basis for bacterial identification. Mol Microbiol. 1997;26(5):1005-11.

18. Untergasser A, Cutcutache I, Koressaar T, Ye J, Faircloth BC, Remm $M$, et al. Primer3-new capabilities and interfaces. Nucleic Acids Res. 2012:40(15):e115.

19. Koressaar T, Remm M. Enhancements and modifications of primer design program Primer3. Bioinformatics. 2007;23(10):1289-91.

20. Ye J, Coulouris G, Zaretskaya I, Cutcutache I, Rozen S, Madden TL. PrimerBLAST: a tool to design target-specific primers for polymerase chain reaction. BMC Bioinform. 2012;13:134.

21. Stothard P. The sequence manipulation suite: JavaScript programs for analyzing and formatting protein and DNA sequences. BioTechniques. 2000;28(6):1102.

22. Aghnatios R, Cayrou C, Garibal M, Robert C, Azza S, Raoult D, et al. Draft genome of Gemmata massiliana sp. nov, a water-borne Planctomycetes species exhibiting two variants. Stand Genom Sci. 2015;10:120.

\section{Submit your next manuscript to BioMed Central and we will help you at every step:}

- We accept pre-submission inquiries

- Our selector tool helps you to find the most relevant journal

- We provide round the clock customer support

- Convenient online submission

- Thorough peer review

- Inclusion in PubMed and all major indexing services

- Maximum visibility for your research

Submit your manuscript at www.biomedcentral.com/submit 